\title{
Rainfall-runoff temporal variability in Kermanshah province, Iran and distinguishing anthropogenic effects from climatic effects
}

\author{
P Ghafarian*, S Gholami, E Owlad and H Gerivani \\ Department of Atmospheric Science, Iranian National Institute for Oceanography and \\ Atmospheric Science, Tehran, Iran. \\ ${ }^{*}$ Corresponding author.e-mail: p.ghafarian@inio.ac.ir
}

Investigation of changes in rainfall and runoff patterns in various regions and determining their relationship in the sense of hydrology and climatology are of great importance, considering those patterns efficiently reveal the human and natural factors in this variability. One of the mathematical methods to recognise and model these fluctuations is Wavelet Analysis. This is a spectral method used in multivariate analysis and also tracing fluctuations in temporal series. In this study, continuous wavelet transformation is used to identify temporal changes in rainfall-runoff patterns. The hydrological and rain gauge data were collected from in situ measurements of Kermanshah province located in the western border of Iran. Precipitation anomalies were reconsidered in a number of stations, including Kermanshah, for a period of 55 years (1955-2010) and discharge of Gamasiab River in Polchehr station, discharge of Khoram Rood River in Aran-Gharb station and discharge of Gharasoo River in Polekohne station. In addition, anomalies of the climatic teleconnections were studied to emphasise the climatological effects on the runoff pattern in the region. The role of natural and anthropogenic effects (land use changes) has been distinguished and identified, using the comparison of the teleconnections and hydrological data. The results achieved from three stations show that there was an approximate correlation between rainfall, runoff and teleconnections until the year 1995; however, after 1995, a great difference appeared among them, specifically for the Aran-Gharb station (Khoram Rood River). The post-1995 slope of cumulative standardised anomaly is much steeper in the case of runoff compared to rainfall. As there were no significant climate changes in the region, it could be concluded that the runoff decrease is not caused by climate changes, but by anthropogenic effects, human interventions and extra water usage from the surface and underground water resources for agriculture and economic purposes.

\section{Introduction}

Investigation of the rainfall-runoff varying patterns and changes in discharge of the rivers in various regions, and determining their relation in climatology and hydrology is important because characterising these patterns will show the effective natural and anthropogenic factors. Rainfall is an important climate factor, which has significant impacts on agricultural production and national economic development (Kuang et al. 2000).

One of the investigation methods used to detect these oscillations and simulate them is the spectral method. Spectral methods including general spectral analysis and wavelet analysis are among the statistics branches with an ever-increasing application in different sciences including Geophysics, Meteorology, Hydrology and Climatology (Kim 2004).

Keywords. Runoff; rainfall; wavelet analysis; Kermanshah; climate. 
Spectral analysis has an effective role in the separation of temporal series from their fundamental frequency components, but unfortunately, the time information will be lost after the separation. It means that when you are looking at the spectral analysis of a temporal series, it is impossible to specify when these components occurred over the temporal series. Meanwhile, the wavelet analysis is an efficient method to analyse temporal series variability and to determine the temporal series prevailing modes information in local form and time-frequency domain. This technique is one of the spectral methods used in multi-scale analysis and detecting the oscillations along with the temporal series (Holschneider 1995).

Continuous Wavelet Transform (CWT) is a temporal-frequency representation of the temporal series and is applied for different types of climatology data (Meyers et al. 1993; Gu and Philander 1995; Lau and Weng 1995; Wang and Wang 1996).

Being a signal's time-scale analysis method, wavelet transform is better than Fourier transform due to its high-resolution features, good localization both in time and scale domains and its capacity of analysing signals at multi-time scales (Clemen 1998; Nener et al. 1999). In addition, wavelet analysis is capable of detecting the jump features of the signals. Therefore, this method has been applied in the climate multi-time scale analysis (Xu et al. 2005).

The Fourier spectral analysis has been often used in recognising trends, but its use is limited due to non-stationary data restriction, such as precipitation and runoff records, which show a

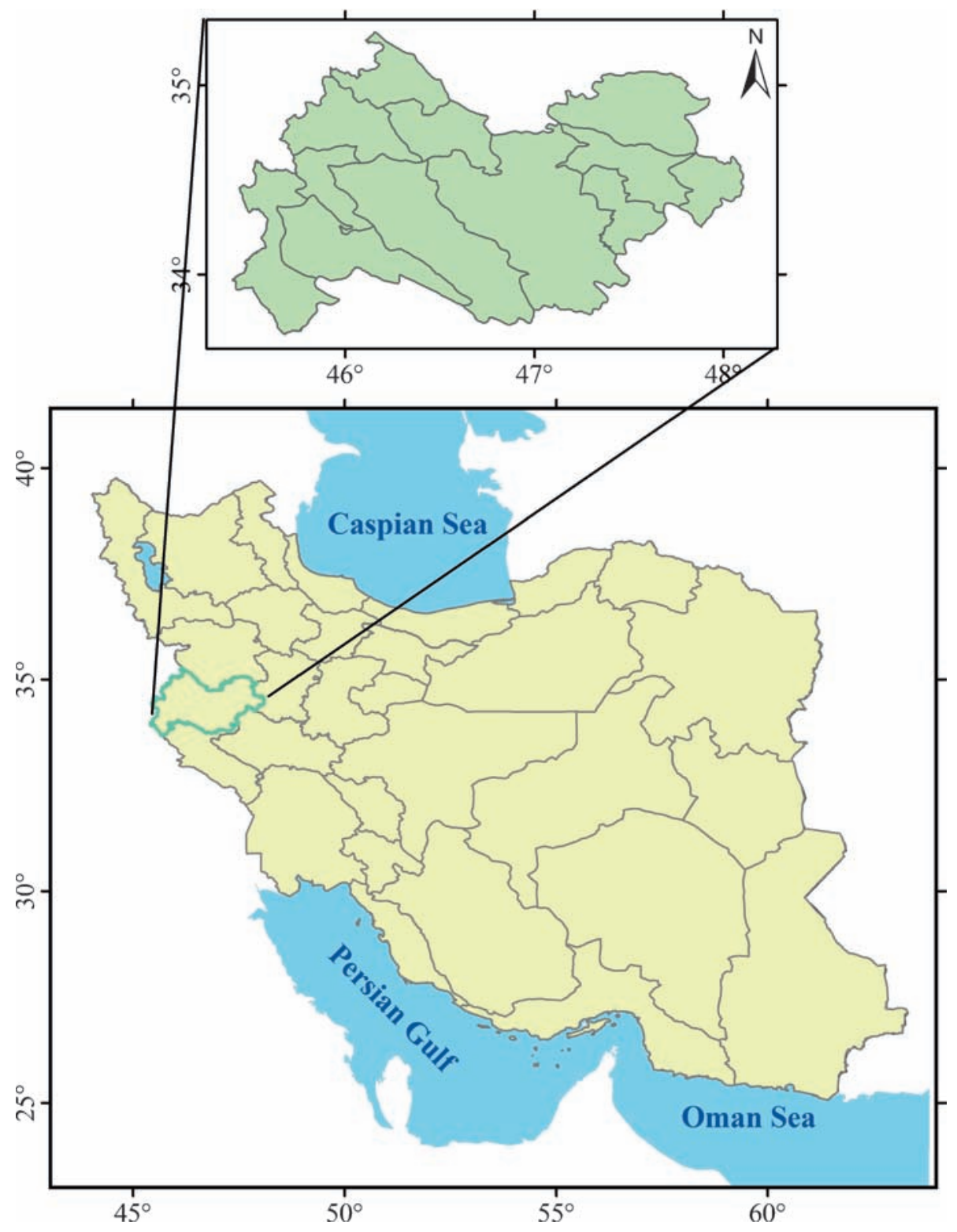

Figure 1. Location of the Kermanshah province in western border of Iran. 
periodic component. The CWT provides a time scale representation of the signal and has been used recently to analyse climatic data (Nakken 1999).

In many studies, wavelet transform is mainly used to analyse the multi-time scale characteristics of the annual temperature and rainfall. Many studies have been conducted before using wavelet analysis, in order to investigate the rainfall-runoff trends. Long-term studies using spectral methods to manage the floods, as well as seasonal circulations and long-term trends are important. Many studies have been conducted using this method and the correlation method over rainfall temporal series. Nevertheless, these studies have not been related to existing trends in runoff temporal series. Smith (1995) compared the discharge and precipitation in Avooka River catchment in northwest Victoria and showed the changes in both discharge and rainfall temporal series from the early 1970s. He found that changes in discharge are not a direct effect of precipitation increase, but a result of changes in the rainfall-runoff relationship.

Many studies have identified the relationship and trends of East Australian rainfall and the El Nino Southern Oscillation (ENSO) (e.g., Stone and Auliciems 1992; Zhang and Casey 1992; Drosdowsky 1993; Nicholls and Kariko 1993; Opoku-Ankomah and Cordery 1993; Suppiah and Hennessy 1996; Kane 1997). These studies, however, have not been linked to trends in runoff temporal series. Results using the Morlet wavelet show that the variability of rainfall and runoff, as well as their relationship, has changed over time. Wavelet spectrum analysis shows a change in dominant frequency since the 1950s. Climate-induced catchment response relates to a short time scale (27-32 months), over the period 1911-1996. The relationship between the SOI (Southern Oscillation Index) and rainfall is stronger from the $1950 \mathrm{~s}$ on, with a dominant frequency of SOI at 27 months. The nonstationary, multi-scale temporal series analysis could be important in floodplain management and development decisions, for the insurance industry and engineering, through identifying past changes, detecting stream flow response to climate changes, and facilitating the future flood and drought predictability (Nakken 1999).

The main purpose of the present paper is to investigate hydrological changes in the Gamasiab, Khoram Rood and Gharasoo River catchments, and to provide further insight into the nature of runoff changes in the recent half century due to changes in rainfall regime and human interference in the catchments. The Fourier spectral analysis method is used to detect the trends, and the CWT method was applied to detect the temporal changes in precipitation and runoff. In addition, this method has been used to distinguish and discrete the climatologic and anthropogenic components, caused by human changes in land use. In section 2 , the study region is described. In section 3 , data and methodology used in this research are

Table 1. Geographical coordinates of the precipitation and runoff gauging stations.

\begin{tabular}{lllll}
\hline & \multicolumn{3}{c}{ Elevation } & \\
& River & $(\mathrm{m})$ & Latitude & Longitude \\
\hline $\begin{array}{l}\text { Hydrology station } \\
\text { Polechehr }\end{array}$ & Gamasiab & 1270 & 34.33 & 47.42 \\
Aran-Gharb & $\begin{array}{l}\text { Khoram } \\
\text { Rood }\end{array}$ & 1440 & 34.58 & 47.91 \\
Polekohme & Gharasoo & 1260 & 34.32 & 47.13 \\
$\begin{array}{l}\text { Synoptic station } \\
\text { Kermanshah }\end{array}$ & & & & \\
\hline
\end{tabular}

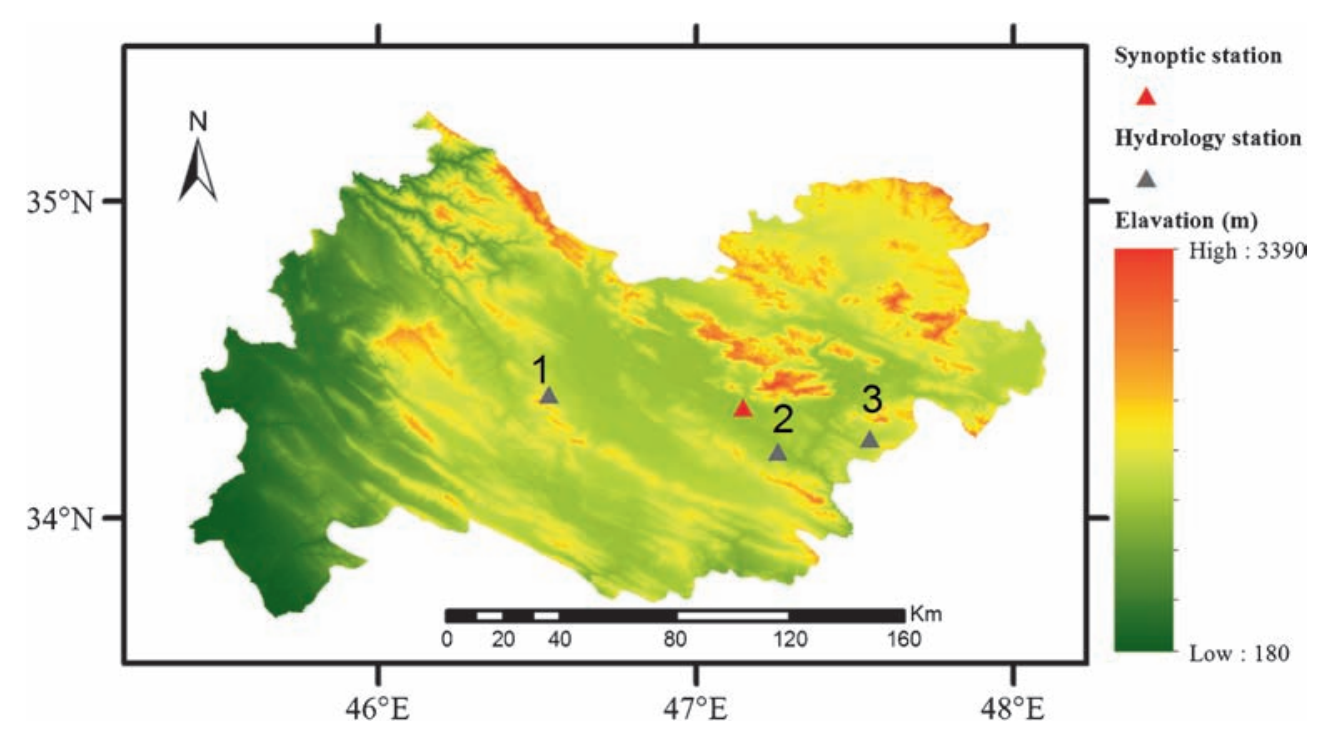

Figure 2. Position of the hydrological stations: (1) Polekohne (Gharasoo River catchment), (2) Polechehr (Gamasiab River catchment), and (3) Aran-Gharb (Khoram Rood River catchment). 
illustrated. In section 4, the results are presented and finally, section 5 gives a summary of the work and discussion about the results.

\section{Study regions}

Iran has a very complicated climate: hot and dry in central deserts, monsoon rainfall in the south-east, dry and cold in the north and wet and mild in the Caspian Sea coasts. Generally, about $70 \%$ of the average rainfall in the country falls between November and March. Rainfall varies in seasons and years. Precipitation is sometimes concentrated locally, but violent storms cause erosion and local flooding, especially in the winter months. A small area along the Caspian Sea coast has a very different climate; here, the rainfall is heaviest from


Figure 3. (a) Cumulative standardized anomaly of Kermanshah rainfall; (b) cumulative standardized anomaly of runoff in Gamasiab River catchment in Polechahr station, Khoram Rood River catchment in Aran-Gharb station and Gharasoo River catchment runoff in Polekohne station in the period of 1955-2010. Horizontal axis is the statistical period and vertical axis is the standardized anomaly. 

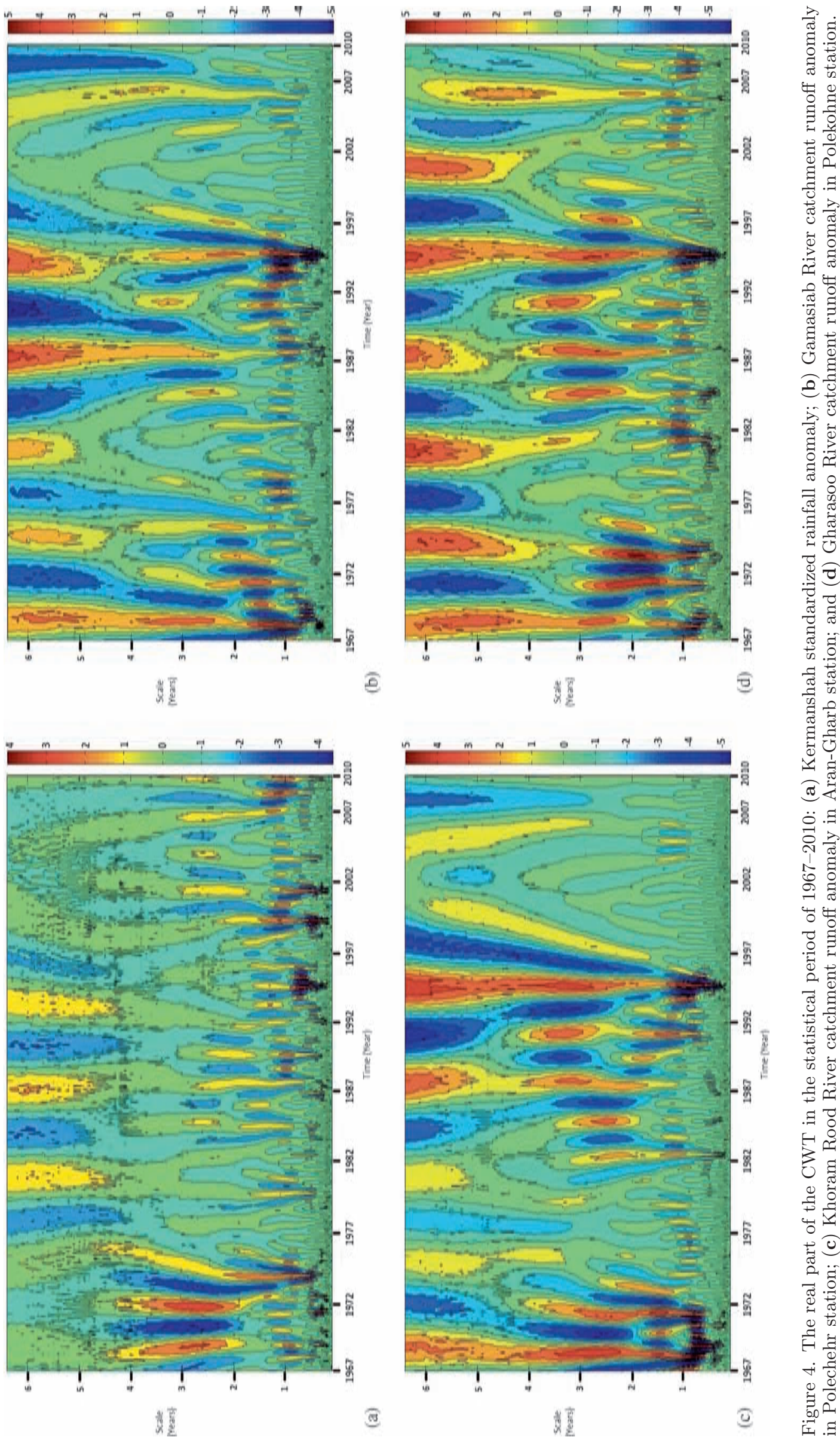
the late summer to mid-winter, although it falls throughout the year (Rasuly et al. 2012).

Kermanshah province of Iran is located in the west of Iran (figure 1) and is one of the relatively wet parts of the country, with an average rainfall of near $500 \mathrm{~mm}$ per year. According to the De Martonne climate index, this region has a Mediterranean climate (precipitation between 400 and 500 $\mathrm{mm}$ per year) (Rajabi and Shabanlou 2012).

\section{Data and methods}

\subsection{Data}

In this study, hydrological and synoptic data received from the selected stations in Kermanshah province were used. Data related to precipitation of Kermanshah synoptic station, Gamasiab River catchment runoff in Polechehr station, Khoram

Table 2. Existing rainfall components in the anomaly temporal series.

Parameter Precipitation in Kermanshah
Period

Seasonal, less than 6 months

Approximately 1-year period

Approximately 3-year period

Approximately 5.5-year period
Exists in a scattered form; the predominant power belongs to the periods of 19691973, 1994-1995, 1998-1999, and 2001. In some periods specifically in years from 2002 to 2010 , the seasonal periods of less than 6 months have experienced intense weakness. Exists from the beginning of the period and gently shifts to the higher frequencies, and in the period of 1973-1974, it was intensified and totally developed in a 6-month to 2-year period. It diminished from 1975 to 1979 and intensified again in the period of 1979-1981. It weakened in the period 1981-1983 and the cycle exists in the next period up to the end of the statistical period; in some temporal periods it is extremely intensified.

Exists from the beginning of the period until 1974 with high intensity. The centrality of the periodicity is about 3 years. It weakened from 1974 to 1983 intensely, and lightly intensified from 1983 to 1991; but the shift occurred towards lower periodicities (2-2.5 years).

Again, the cycle weakened in the period of 1991-1998 and it is lightly intensified from 1998 until the end of the period, in about 2-3 years.

In the beginning of the period, it is highly weak but intensified gently from the year 1977. The situation continues until the year 1997. From the year 1997 until the end of the period, the periodicity pattern is highly weakened.

Table 3. Runoff components of Khoram Rood River catchment in anomaly temporal series.

Parameter Khoram Rood River catchment runoff

Period

Seasonal, less than 6 months

Approximately 1-year period

Approximately 3-year period

Approximately 5.5-year period
Exists extremely scattered. In years 1968 1994-1995 is more intense. In other periods, the intensity of seasonal variability is very weak and after 1996 until 2010, the components are weakening intensely.

This periodicity shows a light shift in the range of 1-2 years among the periods. In some periods, there are two periodicity branches and the prevailing periodicity is about 1 year. In the beginning of the statistical period, it has a high power in two branches of 1 and 1.5 years, while in some occasions the power of the spectrum is highly weakened. Since 1989, intensification of the power has occured; it reaches the maximum power in the period 1993-1995. From 1996 to 2003, it is highly weakened and with a light intensification in the period of 2004-2006, the weakening continues until the end of the period.

From the beginning of the period until the year 1973, it exists with an appropriate intensity, which shifts to lower periodicities. In the period of 1974-1981, it weakened completely and then the shift appears towards higher periodicities until 1998, it is intensified again. Since the period of 1998-2005, it weakened severely and with a light intensification, the trend of weakening continues.

At the beginning of the period, it is weak but after the year 1977, it is lightly intensified and this situation continues until 1997. Since 1997 until the end of the period, the periodicity pattern is intensely weakened. 
Rood River catchment runoff in Aran-Gharb station and Gharasoo River catchment runoff in Polekohne station were analysed (figure 2). As shown in figure 2 , stream gauges are located nearby and the terrain is relatively flat, so all three stream gauges are governed based on the same hydrological processes.
The list of precipitation and runoff gauging stations used in the analysis are given in table 1 . The data were standardised for a 55 -year period from 1955 to 2010, in order to calculate the anomaly and plot the cumulative diagram for the anomalies. In addition, the data of a 43-year period (19672010) was used for spectral and wavelet analysis.

Table 4. Runoff components of Gamasiab River catchment in anomaly temporal series.

Parameter Gamasiab River catchment runoff

Period

Seasonal, less than 6 months

Approximately 1-year period

Approximately 3-year period

Approximately 5.5-year period
Exists highly scattered. In years 1968 and 1994-1995, it is more intense. In other periods, the intensity of the seasonal variability is very weak and since 1996 until the year 2010, intense weakening of the components occurred.

The periodicity shows a little shift in the range of 1-2 years among the periods. In some periods, it appears in two periodic branches and the prevalent periodicity is about 1 year. In the beginning of the statistical period, it has a high power and in occasions the power of the spectrum decreases lightly. Since 1987, the intensification of the power has started again and in the period of 1992-1995, it reaches the maximum power. In the period of 1997-2003, it weakened extremely and with a little intensification in the period of 2004-2006, the weakening trend continues until the end of the statistical period.

It exists from the beginning of the period to the year 1978 with an appropriate intensity and a light intensity decrease in some occasions. From 1978 to1982, it weakened completely and then intensified again until 1998. In the period of 19982003 , it weakened and was intensified lightly until the end of the period.

From the beginning of the period, this periodicity exists with high intensity but in 1982-1996, it reaches the maximum level. From 1998 to 2003, with a change in the pattern, the power weakened intensely. However, until the end of the period, it is intensified as the lower periodicities appear.

Table 5. Runoff components of Gharasoo River catchment in anomaly temporal series.

Parameter Gharasoo River catchment runoff

Period

Seasonal, less than 6 months

Approximately 1-year period

Approximately 3-year period

Approximately 5.5-year period
Exists scattered. In the years 1968, 1973, 1980-1982, 1985 and 1994-1995, it is more intense. In other periods, the intense of seasonal variability is very weak and after the year 1996 until 2010, the intense weakening of components occurred.

This periodicity shows some shifts in the range of 1 to 2 years, among the periods. In some periods, there are two alternative branches and its prevalent periodicity is about 1 year. In the beginning of the statistical period, it has a high power in two branches at about 1 and 1.5 years. In some occasions, the power of the spectrum decreased lightly. In the period of 1981-1983, a little increase of power occurred. In the period of 1993-1995, a high power appears. From 1996 to 2002, it extremely weakened and from 2003 until the end of the period, the power of spectrum in a 1-year periodicity increased a little.

From the beginning of the period until the year 1978, it exists with appropriate intensity that in the period of 1971-1974 it is more intense and with shifting to a 2-year periodicity, the weakening of the component has occurred. From the period of 1981-1976, it weakened completely and then intensification of power appears in 2.53 year periodicity until the year 1998. From 1999 until the end of the period, this component remains at low intensity in a 2-year periodicity.

From the beginning of the period, this periodicity exists with high intensity, which is prevalent in the whole statistical period. Since 2003, the power weakened somehow and shifts towards lower frequencies. 


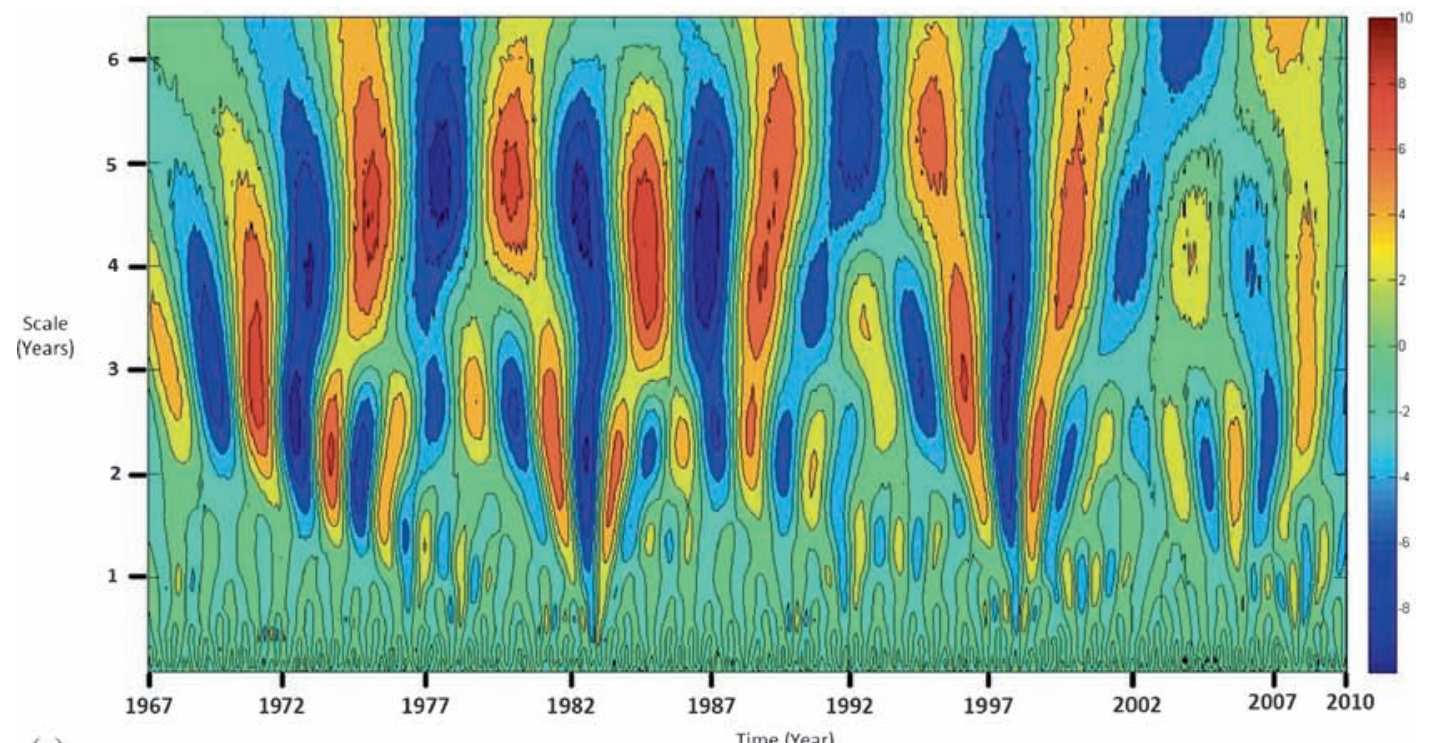

(a)
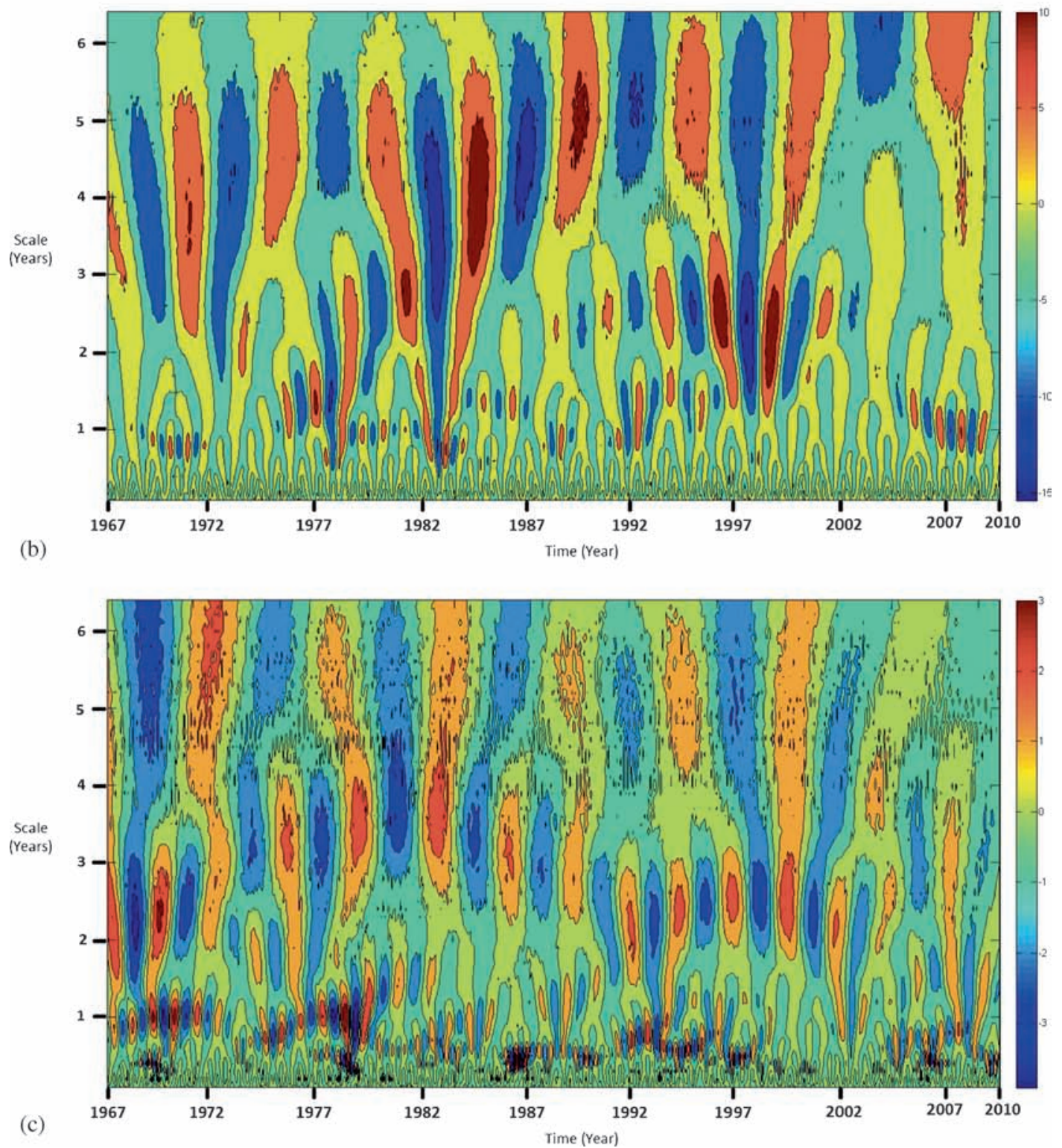

Figure 5. The real part of the CWT in the statistical period of 1967-2010: (a) for SOI; (b) for NOI; and (c) for NAO. 
Data quality control was performed by deletion of the outlier data as well as those data with obvious errors, and replacing them with the mean values of each period.

\subsection{Method}

In this study, CWT was used to determine the temporal variability of the rainfall and runoff as well as their relationship. The wavelet analysis was also applied to analyse the rainfall and runoff records of precipitation in the Kermanshah synoptic station, Gamasiab River catchment runoff in the Polechehr station, Khoram Rood River catchment runoff in the Aran-Gharb station and Gharasoo River catchment runoff in the Polekohne station, as well as the large-scale circulation indices.

\subsection{Rainfall and runoff anomalies}

The standardised anomaly $R_{i j}^{\prime}$, which removes seasonal fluctuations and short-term biases was utilised in the CWT and spectrum analysis according to (Nakken 1999);

$$
R_{i j}^{\prime}=\left(\frac{R_{i j}-\bar{R}_{j}}{\sigma_{j}}\right),
$$

where $R_{i j}$ represents monthly averaged observed data in the year $i$ and the month $j$, and $\bar{R}_{j}$ and $\sigma_{j}$ are the long-term mean and standard deviation of each successive month $j$, respectively. The standardised anomalies are summed over each successive month $j$, in each successive year $i$, i.e.,

$$
a_{i, j}=\sum_{i=1}^{n} \sum_{j=1}^{m} R_{i j}^{\prime},
$$

where $n$ is the total number of years and $m$ the total number of months in the year. The appropriate wavelet should have a similar pattern to the signal. For this reason, the wavelet function used in the present analysis is the Morlet (1983) wavelet, as it reveals peaks and troughs in wavelike signals such as rainfall and runoff records. The complexvalued Morlet function (a modulated Gaussian) can be approximated by

$$
\psi(t)=\frac{1}{\pi^{\frac{1}{4}}} e^{i 2 \pi f_{0} t} e^{-\frac{t^{2}}{2}}
$$

where $t$ represents the time, $f_{0}$ non-dimension is frequency and $\pi^{\frac{1}{4}}$ is the normalisation factor (the wavelet will have a single energy). The CWT is defined as the sum of all the real signal times, $s(t)$, multiplied by the scaled (stretched or compressed) and shifted versions of the wavelet function $\psi$, i.e.,

$$
C(a, b)=\int_{-\infty}^{+\infty} s(t) \psi_{a, b}^{*}(t) d t
$$

(e.g., Chui 1992; Daubechies 1992; Ogden 1997), where the wavelet coefficients, $C$, are the result of the CWT of signal $s(t)$. The scale or dilation parameter, $a$, scales a function by compressing



Figure 6. Time series of cumulative indices of SOI, NOI and NAO in the statistical period of 1955-2010. 
or stretching it, while $b$ is the translation of the wavelet function along the time axis.

$$
\psi_{a, b}(t)=\frac{1}{\sqrt{a}} \psi\left(\frac{t-b}{a}\right) .
$$

The transformed wavelet shifts along the temporal series and results in wavelet transform factors. The dimensioned wavelet could be stretched or compressed along the temporal series. Here, the
$\mathrm{C}$ wavelet factors are the results of $\mathrm{CWT}$ of the $s(t)$ signal.

\subsection{Climatic teleconnections}

Climatic teleconnection generally refers to the linkage of seemingly unrelated climate anomalies over long distances. Although the notion of teleconnection was recognised many years ago (e.g., Hildebrandsson 1897; Walker 1924), the first
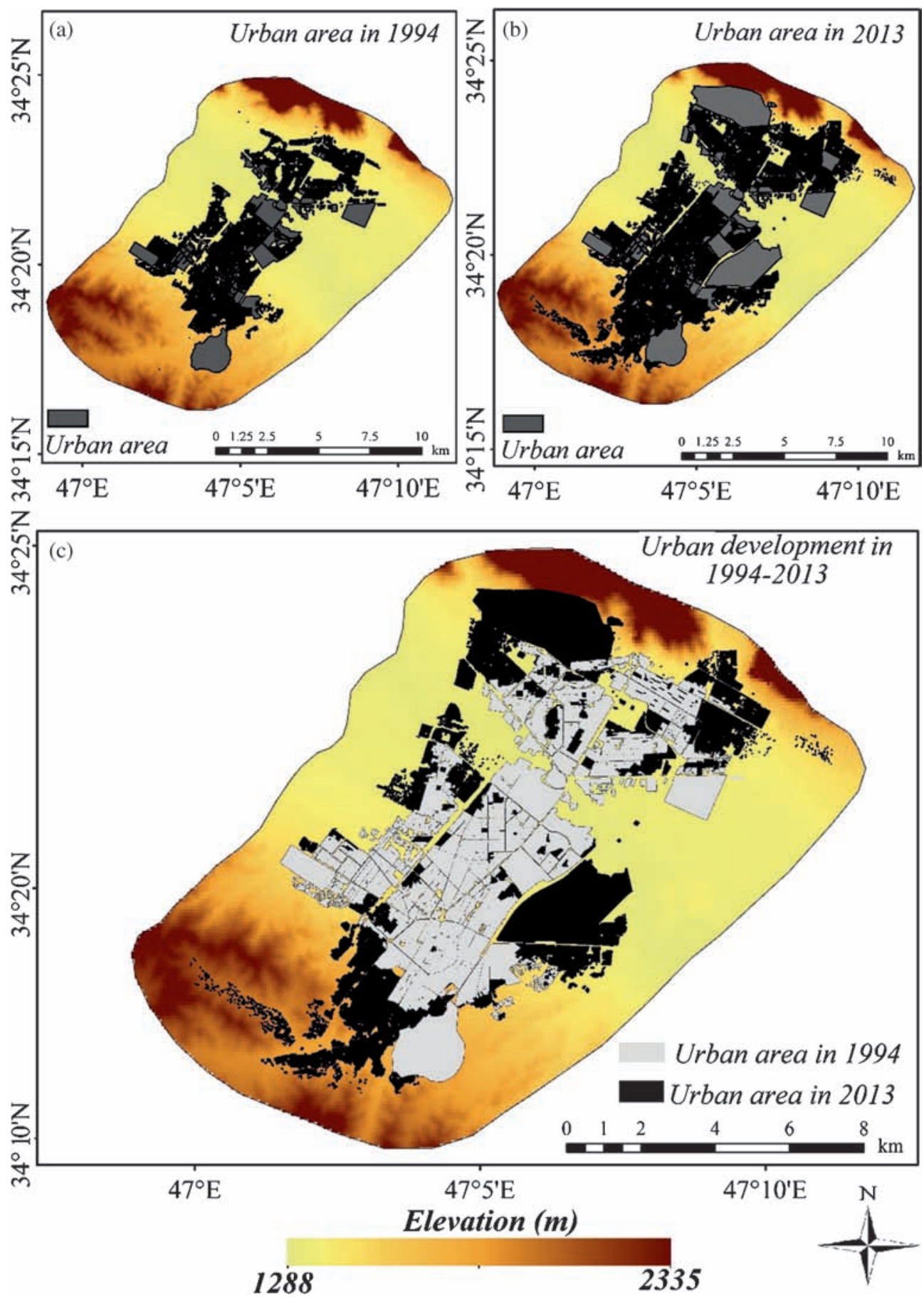

Figure 7. Urban development in Kermanshah. 
known use of 'climatic teleconnections' was by Ångström (1935) in pointing to the north-south dipole atmospheric anomaly pattern, now referred to as the North Atlantic Oscillation (NAO). Wallace and Gutzler (1981) defined teleconnections as "significant simultaneous correlations among the temporal fluctuations of the meteorological parameters at highly separate points on Earth" (Liu and Alexander 2007). In this research, the Southern Oscillation Index (SOI), Northern Oscillation Index (NOI) and the North Atlantic Oscillation Index (NAO) are used as large-scale indices for investigation.

\section{Results}

Applying the above equations, the cumulative standardised anomaly of rainfall for Kermanshah province was achieved. The results of analysis for precipitation of synoptic station of Kermanshah, Gamasiab River catchment, Khoram Rood River catchment and Gharasoo River catchment in the statistical period under study are depicted in figure 3 . In the cumulative anomaly diagram, the oscillations with positive slope represent positive anomalies, and the oscillations with negative slope show negative anomalies in a specific period. Figure 3 shows cumulative anomalies for both precipitation and runoff, where the standardised anomalies are summed over each successive month $j$, in each successive year $i$ (the months with missing data have been ignored). A negative slope in figure 3 indicates that rainfall or runoff values are less than the long-term average and a positive slope represents the values that are higher than the average.

A comparison of rainfall and runoff anomaly variability (figure 4) shows a great similarity between the minimum and maximum wavelet coefficients for the rainfall and runoff data. In a nearly 6-year scale, the runoff data has a strong periodicity pattern from the beginning of the statistical period until the year 1998 and they are in good conformity with the same pattern's rainfall data.

Tables $2-5$ show a summary of the periodicity component's characteristics in all under study stations, in order to have a general view to what figure 4 illustrates. Figure 5 shows the real part of the CWT in the statistical period of 19672010 for teleconnection indices. With an overall look, more similarities in more than one-year returning periods is recognized. Indeed a returning period of less than one year is seen in NOI and NAO indices. The same situation is also seen in the CWT figures of runoff (especially before 1995). After 1995, the Gharasoo catchment has a returning period of one year and less; this confirms the less land use changes in this catchment in comparison with the two other catchments (Gamasiab and Khoram Rood). Figure 6 shows the cumulative indices in the statistical period 1955-2010. For instance, the positive slope in the period 1973-1975 represents La Nina and the negative slope refers to El Nino events. As we see in figure 6, there is no stable pattern in these temporal series; moreover, the SOI and NOI are highly correlated.

In order to get a better view of the anthropogenesis effects, the urban development in Kermanshah province is applied (figure 7). As Maleky and Razavi (2013) mentioned, many agricultural lands changed to urban and residential lands. The maximum changes happened in ranges and agricultural lands (54.13 and 45.3 hectares, respectively), both transformed to the residential area. It is evident that some parts of residential areas advanced towards Gharasoo River. This happened on the north-west side of the river (Maleky and Razavi 2013).

\section{Conclusions}

In this research, the relationship between rainfall and runoff variability in catchments of Gamasiab, Khoram Rood and Gharasoo Rivers were analysed. Wavelet analysis was used to identify and distinguish the climatic components of the hydrological cycle from other trends such as land use changes. The first step in identifying the response of the river flow to the climatological variations is to recognise the effects of the phenomena related to the large-scale circulations. This was conducted by investigating the three basic indices SOI, NOI and NAO. Although the relation between rainfall and runoff anomalies was investigated in this study using the indices, future works may include analysis of the temperature records, as an alternative for evaporation.

Analysis of the rainfall and runoff standardised anomalies showed that the decrease of the cumulative rainfall anomaly (from 1995 until the end of the study period) affects the intense decrease of runoff in the under study hydrological stations; and that the effect is more considerable in comparison to the earlier temporal periods. The post-1995 slope of cumulative standardised anomaly is much steeper in the case of runoff compared to rainfall. This implies that rainfall is not the only reason for decreasing runoff. On the other hand, regarding the intense decrease of runoff in the aforementioned date, it can be concluded that the reasons could be land use changes, urbanisation and irregular use of surface and undersurface water resources. This is because, although the relationship between rainfall and runoff is not linear, if the decrease in runoff after 1995 caused just by rainfall decrease, 
the slopes of the cumulative rainfall and runoff should remain the same; but it is clearly seen that the slope of runoff is much more intense. In addition, wavelet analysis was used to investigate the precise variability of different components in temporal series. The results of the wavelet analysis for rainfall and runoff standardised anomalies in the stations under study showed similar frequency components in the rainfall and runoff. The component with a 1-year period in the rainfall anomaly temporal series after the year 1995 did not affect the runoff temporal series. This effect was a little more just in the Gharasoo River catchment. This could be related to the land use changes in recent years. Relocation and changes in the intensity of different frequency components in the statistical period was also investigated using this method.

In order to consider the climatic factors which probably affect the rainfall and runoff in the region, three indices SOI, NOI and NAO were examined using temporal series, spectral and wavelet analysis. The results did not show any significant relation between the indices and the rainfall and runoff anomalies. This part of the study requires more detailed work because the precipitation in the western part of Iran is usually seasonal and more study is needed on the indices season by season.

Climatic oscillations (change in rainfall, temperature, etc.) have no significant effect in the changes of the runoff in the region. It could be concluded that the decrease in runoff was more related to anthropogenic effects caused by human as well as water withdrawal from the surface and undersurface resources for agricultural and economic purposes. This would be a major concern for the provincial authorities and their future planning.

\section{Acknowledgements}

The current research project has been supported by a grant $(92 / 130 / 59292)$ by the research committee of Kermanshah Regional Water Company. The authors appreciate the committee for the financial supports, and would also like to thank the Iranian Meteorology Organization (IRIMO) and Kermanshah Regional Water Corporation for providing the data. Finally, the authors express their gratitude to Mohammad Saeed Najafi for creating figure 7 for this research.

\section{References}

Ångström A 1935 Teleconnections of climatic changes in present time; Geogr. Ann. 17 242-258.

Chui C K 1992 An Introduction to Wavelets, Vol. 1 of Wavelet Analysis and its Applications; Academic Press, Boston.
Clemen T 1998 The use of scale information for integrating simulation models into environmental information systems; Ecol. Model. 108(1) 107-113.

Daubechies I 1992 Ten Lectures on Wavelets, Vol. 61 of CBMSNSF Regional Conference Series in Applied Mathematics; Society for Industrial and Applied Mathematics, Philadelphia.

Drosdowsky W 1993 An analysis of Australian seasonal rainfall anomalies: 1950-1987: II. Temporal variability and teleconnection patterns; Int. J. Climatol. 13 111-149.

Gu D and Philander S G H 1995 Secular changes of annual and interannual variability in the tropics during the past century; J. Climate 8 864-876.

Hildebrandsson H H 1897 Quelquerecherchessur les entresd'action de l'atmosphere, K. Sven. Vetenskapsakad; Handl 29 1-33.

Holschneider M 1995 Wavelets, analysis tool; Oxford Univ. Press, New York.

Kane R P 1997 On the relationship of ENSO with rainfall over different parts of Australia; Aust. Meteorol. Mag. 46(1) 39-49.

Kim S 2004 Wavelet analysis of precipitation variability in northern California, USA; KSCE J. Civ. Eng. 8(4) $471-477$.

Kuang Z, Ji Z Z and Lin Y H 2000 Wavelet analysis of rainfall data in North China; Clim. Environ. Res. (in Chinese) 5(3) 312-317.

Lau K M and Weng H 1995 Climate signal detection using wavelet transform: How to make a temporal series sing; Bull. Am. Meteorol. Soc. 76(12) 2391-2402.

Liu Z and Alexander M 2007 Atmospheric bridge, oceanic tunnel, and global climatic teleconnections; Rev. Geophys. 45(2) RG2005.

Maleky M and Razavi B S 2013 Evaluation of development and changes in land use using different satellite image processing and remote sensing techniques (Case study: Kermanshah, Iran); Res. J. Environ. Earth Sci. 5(10) $567-576$.

Meyers S D, Kelly B G and O'Brien J J 1993 An introduction to wavelet analysis in oceanography and meteorology with application to the dispersion of Yanai waves; Mon. Wea. Rev. $1212858-2866$.

Morlet J 1983 Sampling theory and wave propagation. In: Issues in Acoustic Signal/Image Processing and Recognition (ed.) Chen C H, Vol. 1 of NATO ASI Series. Springer-Verlag, New York, pp. 233-261

Nakken M 1999 Wavelet analysis of rainfall-runoff variability isolating climatic from anthropogenic patterns; Environ. Model. Softw. 14(4) 283-295.

Nener B D, Ridsdill-Smith T A and Zeisse C 1999 Wavelet analysis of low altitude infrared transmission in the coastal environment; Infr. Phys. Technol. 40 399-409.

Nicholls N and Kariko A 1993 East Australia rainfall events: Interannual variations, trends, and relationships with the southern oscillation; J. Climate 6 1141-1152.

Ogden R T 1997 Essential Wavelets for Statistical Applications and Data Analysis; Birkhäuser, Boston.

Opoku-Ankomah Y and Cordery I 1993 Temporal variation of relations between New South Wales rainfall and the southern oscillation; Int. J. Climatol. 13 51-64.

Rajabi A and Shabanlou S 2012 Climate index changes in future by using SDSM in Kermanshah, Iran; J. Environ. Res. Dev. 7(1).

Rasuly A A, Babaeian I, Ghaemi H and ZawarReza P 2012 Temporal series analysis of the pressure of the synoptic pattern centers affecting on seasonal precipitation of Iran; Geography and Development 10th Year (27) 18-21.

Smith N 1995 Recent hydrological changes in the Avoca River catchment, Victoria; Aust. Geogr. Stud. 33(1) 6-18.

Stone R and Auliciems A 1992 SOI phase relationships with rainfall in eastern Australia; Int. J. Climatol. 12 625-636. 
Suppiah R and Hennessy K J 1996 Trends in the intensity and frequency of heavy rainfall in tropical Australia and links with the southern oscillation; Aust. Meteorol. Mag. 45 1-17.

Walker G T 1924 Correlation in seasonal variations of weather IX, Mem; India Meteorol. Dept. 24 275-332.

Wallace J M and Gutzler D S 1981 Teleconnections in the geopotential height field during the Northern Hemisphere winter; Mon. Wea. Rev. 109(4) 784-812.
Wang B and Wang Y 1996 Temporal structure of the southern oscillation as revealed by waveform and wavelet analysis; J. Climate 9 1586-1598.

$\mathrm{Xu} \mathrm{Y,} \mathrm{Li} \mathrm{S} \mathrm{and} \mathrm{Cai} \mathrm{Y} 2005$ Wavelet analysis of rainfall variation in the Hebei Plain; Sci. China. Ser. D 48(12) $2241-2250$.

Zhang X-G and Casey T M 1992 Long-term variations in the southern oscillation and relationships with Australian rainfall; Aust. Meteorol. Mag. 40(4) 211-225.

MS received 10 November 2015; revised 20 May 2016; accepted 6 June 2016

Corresponding editor: Subimal Ghosh 